\title{
Identification of key genes responsible for cytokine-induced erythroid and myeloid differentiation and switching of hematopoietic stem cells by RAGE
}

\author{
Ling Chen ${ }^{1,3}$, Hong Zhang ${ }^{2}$, Ying Shi ${ }^{1}$, Kyung L Chin ${ }^{1}$, Delia C Tang ${ }^{1}$, Griffin P Rodgers ${ }^{1}$ \\ ${ }^{1}$ Molecular and Clinical Hematology Branch (MCHB), National Institute of Diabetes and Digestive and Kidney Diseases (NIDDK), \\ National Institutes of Health, Bethesda, MD 20892, USA; ${ }^{2}$ Z-BioMed, Inc., Rockville, MD 20855, USA; ${ }^{3}$ Department of Medicine, \\ First Affiliated Hospital, Zunyi Medical College, Zunyi 563003, China
}

We utilized a unique culture system to analyze the expression patterns of gene, protein, and cell surface antigen, and the biological process of the related genes in erythroid and myeloid differentiation and switching of hematopoietic stem cells (HSCs) in response to cytokine alterations. Gene-specific fragments (266) identified from five populations of cytokine-stimulated HSCs were categorized into three groups: (1) expressed specifically in a single cell population; (2) expressed in two cell populations, and (3) expressed in three or more populations. Of 145 defined cDNAs, three $(2 \%)$ were novel genes. Protein two-dimensional gel electrophoresis and flow cytometry analyses showed overlapped and distinguished protein expression profiles in the cell populations studied. Biological process mapping of mRNAs expressed in erythroid and myeloid lineages indicated that mRNAs shared by both lineages attended 'core processes,' whereas genes specifically expressed in either lineage alone were related to specific processes or cellular maturation. Data from this study support the hypothesis that committed HSCs (E14 or G14) cells can still be redirected to develop into myeloid or erythroid cells when erythropoietin (EPO) is replaced with granulocyte-colony stimulating factor (G-CSF) under erythroid-cultured condition or G-CSF with EPO in myeloid-cultured environment, respectively. Our results suggest that genes or proteins co-expressed in erythroid and myeloid lineages may be essential for the lineage maintenance and switching in hematopoiesis.

Cell Research (2006) 16:923-939. doi: 10.1038/sj.cr.7310115; published online 5 December 2006

Keywords: lineage switching, hematopoietic stem cells, erythroid/myeloid differentiation, co-expression, biological processes, cytokines

\section{Introduction}

Hematopoietic stem cells (HSCs) have been used in clinical stem cell transplantation with the potential for regenerative medicine. HSCs are capable of self-renewing and potential differentiation; however, the mechanism by which HSCs are differentiated into erythroid and myeloid lineages is not well understood. The gene expression pat-

Correspondence: Griffin P Rodgers

Tel: +1-301-402-2418; Fax: +1-301-480-1373;

E-mail: gprod@helix.nih.gov

Received 8 February 2006; revised 16 October 2006; accepted 18 October 2006; published online 5 December 2006 terns and biological processes associated with differentiation of HSCs have not been previously examined during erythroid and myeloid development. Studies have shown that lineage cells can be converted from one cell type to another by exposure to various transcription factors in hematopoietic cells [1] and by oncogene expression in leukemic cells [2]. Furthermore, the existence of common myeloid progenitors (CMPs), which can be subdivided into erythroid and myeloid lineage cells, has been suggested in normal erythropoiesis and granulopoiesis. In the clinic, abnormality of erythroid or myeloid development was often accompanied by other abnormalities, such as in disorders of myelodysplasia and myeloproliferation and in some leukemias. Thus, the study of gene expression patterns and 
biological processes, in such closely related developmental subpopulations of hematopoietic cells, might provide a fundamental tool not only to elucidate lineage biological activities of development but also to develop potential clinical applications of cell-based therapies.

Analysis of cell populations, which allows physiologically relevant cellular interactions to occur, can provide more useful information than that of single-cell clones [3]. We, therefore, analyzed the gene expression patterns of five hematopoietic cell populations including progenitors and committed-erythroid and -myeloid lineage cells, using a unique switch culture and the rapid-analysis-ofgene-expression (RAGE) technique. RAGE is a flexible, semi-quantitative, and intermediate-scale alternative method based on polymerase chain reaction (PCR) for the analysis of gene expression profiles, which allowed us not only to examine known genes but also to discover new genes. The PCR-based RAGE has been used by Wang et al. [4] to simultaneously identify hundreds of transcripts in transgenic mice. According to the authors, this method is valuable for assaying the order of tens to hundreds of genes in multiple samples and for the reliable detection of changes in gene expression, two-fold and greater. Because of its sensitivity, RAGE-PCR is suitable for studying human bone marrow stem cells, which can only be obtained in small numbers. In this paper, we analyzed HSCs grown in the presence of erythropoietin (EPO) or granulocyte-colony stimulating factor (G-CSF) by RAGE-PCR amplification using 320 primers specific for gene sequences of blood development. The PCR products were identified by searching the GeneSystem $320^{\mathrm{TM}}$ database or DNA sequencing. We also employed twodimensional gel electrophoresis (2-DE) to detect global changes in cellular proteins within these cell populations to compare the protein expression profiles.

Co-expression of erythroid- and myeloid-specific antigens has been reported in malignant hematopoietic cells $[5,6]$ and immature transformed cells [7], but it has not been previously described during these two-lineage commitment and conversion in normal hematopoiesis. In this study, we used CD133 (also known as AC133)-selected, highly enriched HSCs, which have been used to study stem/progenitor cell biology as an alternative to using CD34-selected cells [8-10]. For lineage-specific markers, we used CD13 as a myeloid antigen that is highly expressed on early myeloblast precursors and promyelocytes $[11,12]$ and CD36 as an erythroid marker of proerythroblasts and basophilic erythroblasts of early erythroid precursor cells [13]. We monitored the differentiation and maturation of HSCs by analyzing the expression of cellular surface antigens [14] to test the hypothesis that cross-lineage markers exist simultaneously on normal committed HSCs.
The specific and shared biological processes underlining the differentially expressed genes in erythroid and myeloid differentiation were further exploited with GoSurfer software [15]. GoSurfer is a graphical interactive program for the biological process analysis of cells from comparative gene lists. It uniquely identifies the categories of biological processes contributed by genes or gene products and their hierarchical relationship, and shows these comparison data in a single map of a tree structure [16]. GoSurfer has been used for comparative analysis of gene expression in different tissues [17-20].

The identification of gene expression patterns and changes of common as well as specialized genes in erythroid and myeloid differentiation and switching of HSCs in response to cytokine alterations can provide candidate genes for further studies and may also provide an insight into the mechanisms underlying the regulation of differentiation of these lineages. Our data suggest that the co-expression patterns of some genes, proteins, and cellular surface antigens in these two lineages may be physiologically essential for both normal lineage plasticity and hematopoietic disorders associated with bi-lineage cells. Thus, the study of hematopoietic lineage switch or conversion in normal lineages has the potential for clinical use under specific conditions.

\section{Materials and Methods}

\section{Cell culture}

Human bone marrow $\mathrm{CD} 133^{+}$cells (D0) were grown for 14 days in the erythroid or myeloid culture system with EPO (E14) or GCSF (G14), respectively, in the presence of stem cell factor (SCF, 50 $\mathrm{ng} / \mathrm{ml}$ ), interleukin-3 (IL-3, $10 \mathrm{ng} / \mathrm{ml}$ ), and granulocyte-macrophage colony-stimulating factor (GM-CSF, $10 \mathrm{ng} / \mathrm{ml}$ ) with $30 \%$ fetal bovine serum (FBS) (heat inactivated). The addition of GM-CSF to the erythroid culture system was a modification from a previous report [21], which was made to better understand the effect of EPO versus G-CSF in the switch culture system. E14 cells were washed and recultured for another 14 days with G-CSF (E14 $\rightarrow$ G14), and G14 cells were washed and recultured for another 14 days with EPO $(\mathrm{G} 14 \rightarrow \mathrm{E} 14)$. Control cells were grown for 28 days in a cytokine-free medium or in a medium with EPO (E28) or G-CSF (G28) without switching cytokines. Samples from each cell population were stained with Wright-Giemsa staining.

\section{$R N A$ extraction and $c D N A$ preparation}

Total RNA was isolated from five cell populations with the RNAwiz kit (Ambion, Austin, TX) according to the manufacturer's instructions. The DNase-treated RNA ( 5 to $10 \mu \mathrm{g}$ per sample) was subsequently used to synthesize double-stranded cDNA using a biotinylated oligo (dT) primer and a cDNA synthesis system (Gibco, Gaithersburg, MD). A cDNA integrity kit (Gibco) was used to confirm that the full length of each cDNA was intact. This step was necessary because the RAGE method depends on the integrity of the 3' end of the cDNA. 


\section{Synthesis of specific RAGEtags}

Reagents and kits for RAGEtag preparation were purchased from Kirkegaard and Perry Laboratories Inc. (KPL, Gaithersburg, MD), unless otherwise indicated. RAGEtags representing unique cDNA fragments in both orientations were prepared by using human RAGEtag kits with $400 \mathrm{ng}$ of cDNA from undifferentiated $\mathrm{CD}_{133^{+}}$cells (D0) due to limited cell numbers and $1.5 \mu \mathrm{g}$ of cDNA from each of the four other cell populations (E14, G14, E14 $\rightarrow$ G14, G14 $\rightarrow$ E14). Levels of RAGE-PCR products from each sample were normalized to those of housekeeping genes or rRNA structural genes using RAGEtag standardization gene kits. Each cytokine-treated sample was compared to the D0 cell population, according to the manufacturer's recommended conditions.

\section{Semi-quantitative RAGE-PCR}

The amplified cDNA fragments were used in reverse transcriptase (RT)-PCR experiments. RAGEtags were prepared from the various cell populations ( $2 \mu 1$ of 1:250 dilution of RAGEtags for the D0, E14, and G14 cultures; $4 \mu 1$ for the E14 $\rightarrow$ G14 and G14 $\rightarrow$ E14 cultures) based on the amount that maintains a constant rate of PCR product synthesis for eight different primer pairs in the normalization kit provided by KPL. The RAGEtags were used as templates with five A-primers (Nos. 11, 61, 120, 169, and 192) related to hematopoietic development and with all $64 \mathrm{~B}$-primers; all primers were provided by KPL. Twenty-eight cycles of PCR were performed, each consisting of denaturation at $95{ }^{\circ} \mathrm{C}$ for $30 \mathrm{~s}$, annealing at $60{ }^{\circ} \mathrm{C}$ for $1 \mathrm{~min}$, and extension at $72{ }^{\circ} \mathrm{C}$ for $1 \mathrm{~min}$. The PCR products were separated on $8 \%$ tris-borate-EDTA Pre-cast gels (Invitrogen, Carlsbad, CA) and stained with SYBR ${ }^{\circledR}$ Green from BioWhittaker Molecular Applications (BMA, Rockland, ME).

\section{RAGE-PCR product analysis, cloning, and sequencing}

The differentially expressed RAGE-PCR products were characterized by searching the Capital Genomix GeneSystem $320^{\mathrm{TM}}$ database for amplimers of the observed sizes. Bands that could not be identified in this way were excised from gels, purified with the Qiaquick PCR Purification Kit (Qiagen, Valencia, CA), and cloned into the TOPO pCR2.1 vector (Invitrogen). Plasmids were isolated with the Qiaprep Miniprep Kit (Qiagen). Approximately $400 \mathrm{ng}$ of plasmid DNA was used in each $20 \mu \mathrm{l}$ sequencing reaction, and DNA fragments greater than $100 \mathrm{bp}$ in length were sequenced on a 3100 Genetic Analyzer (ABI Prism).

\section{Gene data analysis}

All sequences or gene fragments were used for BLAST searches against the nonredundant and dbEST databases within the NCBI (http://www.ncbi.nlm.nih.gov) and Celera (http://www.celera. com) databases. Cellular RAGEtags that lacked significant BLAST similarities or deduced protein correspondences were considered as novel genes. RAGEtag sequences that shared at least $95 \%$ identity with human genes greater than $100 \mathrm{bp}$ in length were classified as known genes.

\section{Protein 2-dimensional gel electrophoresis}

Two-dimensional gel electrophoresis (2-DE) was performed according to the protocol provided by the manufacturer of the 2-DE apparatus (Amersham Pharmacia Biotech, Piscataway, NJ). Cells from each of the five cell populations (D0, E14, G14, E14 $\rightarrow$ G14, and $\mathrm{G14} \rightarrow \mathrm{E} 14)$ were disrupted in lysis buffer. Each sample lysate (5 $\times 10^{5}$ cells) was rehydrated overnight in $200 \mathrm{ml}$ of rehydration buffer on an $11 \mathrm{~cm}$ Immobiline DryStrip, pH 4-7 (immobilized pH gradient, Amersham Bioscience, Charlotte, NC). Samples were then subjected to isoelectric focusing on a Multiphor II electrophoresis unit (Amersham Bioscience) for $15000 \mathrm{~V} \cdot \mathrm{h}$. After equilibration, immobilized $\mathrm{pH}$ gradient strips were further processed for second-dimension polyacrylamide gel electrophoresis on ExcelGel SDS XL 12-14. The resulting gels were automatically silver-stained and scanned on a BioRad GS-800 scanning densitometer (BioRad, Veenendaal, The Netherlands). Images were analyzed with PDQuest 6.2 software (BioRad). Specific protein spots were identified by matrix-assisted laser-desorption ionization mass spectrometry (MALDI-MS) coupled with a peptide mass fingerprinting database (Applied Biosystem 4700 Proteomics Analyzer; Applied Biosystems, Foster City, CA) using Mascot Software (Matrix Science Ltd, London, UK). Each individual cell sample was subjected to 2-DE at least twice, and 2DE was conducted on samples from at least two replicate culturing experiments.

\section{Flow cytometry}

Cells from the D0, E14, G14, E14 $\rightarrow$ G14, and G14 $\rightarrow$ E14 populations were stained and subjected to flow cytometry. Cells were stained with antibodies specific for CD133 (using CD133/1 conjugated with phycoerythrin (PE), Miltenyi Biotec, Auburn, CA) to detect stem/progenitor cells, CD36 (conjugated with fluorescein isothiocyanate (FITC)) to detect erythroid precursor cells, or CD13 (conjugated with allophycocyanin (APC)) to detect myeloid precursor cells. Transfected leukemic K562 cells (see below) were also stained with the above antibodies as well as with the FITC-conjugated antibody against glycophorin A (GPA for erythroid). The CD36, CD13, and GPA antibodies and all negative controls were purchased from Pharmingen BD (San Jose, CA). Flow cytometry analysis was conducted using Cell Quest software (Becton Dickinson, San Jose, CA). All reactions were controlled with the appropriate isotype-matched, irrelevant antibody.

\section{Northern blot analysis}

Glia maturation factor gamma (GMFG) cDNA probe (536 bp) was generated by RT-PCR from G14 cells, labeled with $\left[\alpha-{ }^{32} \mathrm{P}\right]$-dCTP (Amersham, Braunschweig, Germany) and used for Northern blot analysis. The primer sequences are 5'-AAA GAA GAG GCC TGT GGA CAG-3' (forward) and 5'-TGG TTG TTC AGG TCC TAG GG-3' (reverse). The Human Multiple Tissue Northern Blots (BD Biosciences Clontech, Heidelberg, Germany) were hybridized with labeled GMFG probe according to the manufacturer's recommendations. A human $\beta$-actin probe (provided with the blots) was used as a control for RNA loading and transfer efficiency.

\section{Transfection of K562 cells with siRNA}

Human leukemic K562 cells were grown in RPMI-1640 medium (ATCC) supplemented with 10\% FBS and 1\% penicillin-streptomycin. Smart Pool ${ }^{\mathrm{TM}}$ GMFG siRNA directed against the sequence of GMFG, along with a negative control, siControl 1, were chemically synthesized by Dharmacon (Lafayette, CO). K562 cells $\left(1 \times 10^{6}\right)$ were transiently transfected with $2 \mu \mathrm{g}$ of GMFG siRNA or control siRNA according to the supplier's instruction for the Nucleofector kit using an electroporation apparatus (Nucleofector System, Amaxa, Koeln, Germany). 


\section{Quantitative RT-PCR analysis}

Total RNA was extracted from K562 cells using TRI reagent (Molecular Research Center). The quality of total RNA was monitored by gel electroporesis. cDNA was prepared and analyzed by using a Bioanalyzer (Agilent Technologies) for quantitative PCR to detect GMFG expression in the transfected K562 cells every 24 h for 96 h. GAPDH was used as a control to assess siRNA specificity. Cells were also harvested for flow cytometry analyses after the treatment with GMFG or control siRNA.

Comparative analysis of genes expressed in erythroid and myeloid cells

The comparative analysis of expressed genes associated with erythroid and myeloid lineages was performed using the GoSurfer analysis tool. GoSurfer takes two lists of genes and maps the genes onto Gene Ontology terms. The Gene Ontology terms are organized in a hierarchical manner with the broad categorical terms 'Biological Process', 'Molecular Function', and 'Cellular Component' at the top of the hierarchy, and more specific terms lower in the hierarchy. GoSurfer visualizes the Gene Ontology hierarchy as a tree structure. For every Gene Ontology term, GoSurfer performs a statistical test to determine if this term is sufficiently biased in its usage so as to annotate one of the two input gene lists. The Gene Ontology terms that are significantly associated with one of the input gene lists but not the other are identified and color-coded on the visualized Gene Ontology tree.

\section{Results}

\section{Morphologic changes of HSCs in response to EPO and} $G-C S F$

To investigate morphologic changes of HSCs in response to EPO and G-CSF during erythroid and myeloid differentiation and switching, CD133 ${ }^{+}$HSCs (D0) were treated for 14 days with either EPO (E14) or G-CSF (G14). EPOtreated erythroid cultures (E14) were subsequently exposed to G-CSF instead of EPO (E14 $\rightarrow$ G14), and G-CSF-treated myeloid cultures (G14) were subsequently exposed to EPO instead of G-CSF (G14 $\rightarrow$ E14), for another 14 days. Approximately 500 600 cells from each cell population were stained with Giemsa staining and evaluated microscopically for different types of cells. Figure 1 shows the morphologic changes that occurred during erythroid and myeloid lineage differentiation and switching. The percentages of different cell types were similar to previous results [21]. Control cells exposed to EPO for 28 days (E28) showed a continuing predominance of erythroid cells; in contrast, control cultures exposed to G-CSF for 28 days (G28) contained granulocytes/macrophages without erythroid lineage cells. Cells in untreated control cultures showed poor prolif-

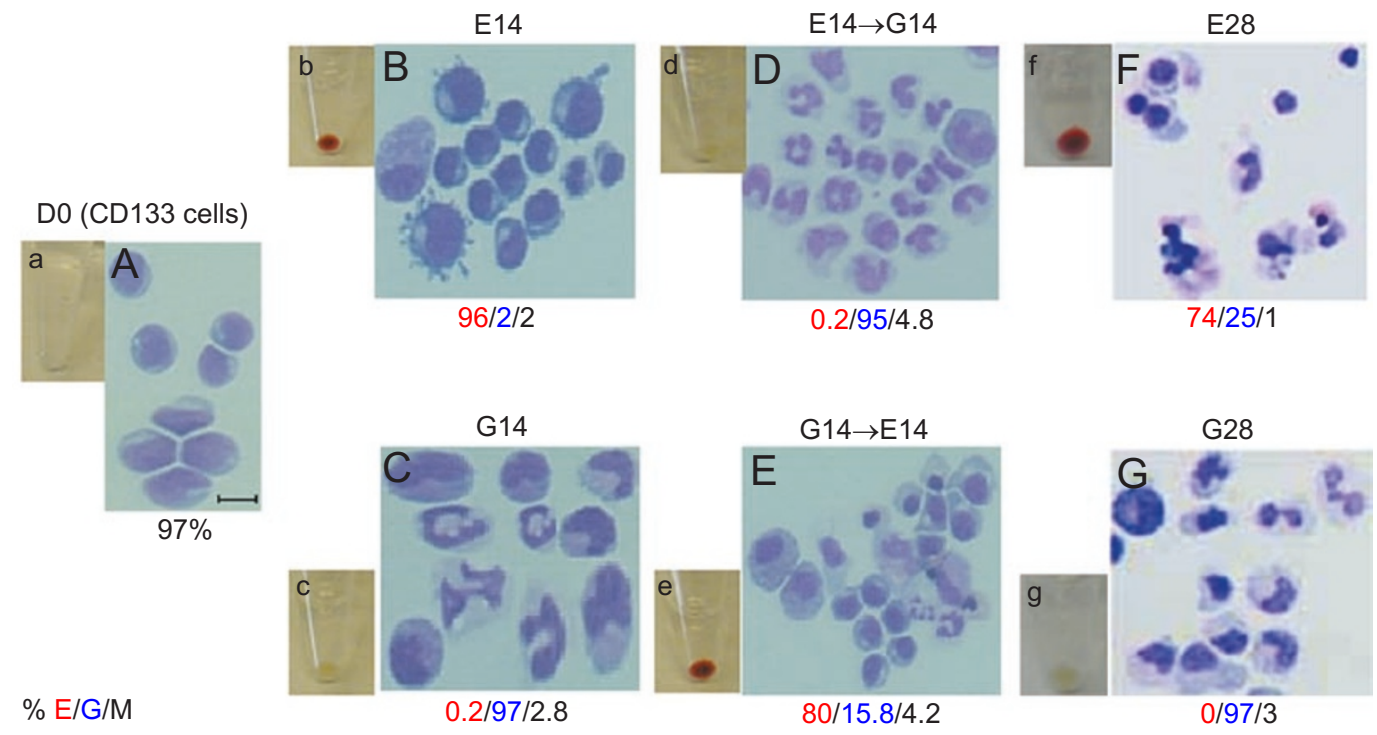

Figure 1 Differentiation of erythroid and myeloid cells from progenitors in response to cytokine stimulation. (A) CD133 ${ }^{+}$cells at the beginning of the culture (D0). (B) Cells induced with EPO for 14 days (E14). (C) Cells induced with G-CSF for 14 days (G14). (D) EPO-stimulated cell cultures exposed to G-CSF for another 14 days in culture (E14 $\rightarrow$ G14), this population of cells had matured to banded and segmented myeloid forms with few erythroid cells. (E) G-CSF-stimulated cell cultures exposed to EPO for another 14 days in culture (G14 $\rightarrow$ E14), which exhibited a majority of erythroid cells, with some myeloid cells. (F and G) Cells cultured with EPO (E28) and G-CSF (G28) for 28 days, respectively, without exchanging the cytokines. (a-g) Cell pellets for each of the cell populations shown in panels A-G. The bar in (A) indicates a length of $10 \mu \mathrm{m}$. The numbers under each population of cells are the average distribution of erythroid (in red), myeloid (in green), and mononuclear (in black) cells. (A-G) Cell spreads stained with Wright-Giemsa stain. Images were acquired using a Nikon UFX-DXII microscope. Original magnification $200 \times$. 
eration, which was consistent with previous observations [21]; the majority of the cells were mononuclear cells and granulocytes, but erythrocytes were not detected.

Gene expression patterns of HSCs in response to EPO and $G$-CSF

To characterize gene expression patterns of HSCs during erythroid and myeloid development and maturation in response to EPO and G-CSF and changes of cytokines, we prepared biotin-labeled cDNA samples from untreated CD133 ${ }^{+}$HSCs (D0) and cytokine-treated E14, G14, E14 $\rightarrow$ G14, and G14 $\rightarrow$ E14 cells. From these five cell populations, 266 specific DNA fragments were amplified by RAGEPCR. Some genes were expressed in only one cell population; others were expressed in two or more cell populations at various levels. Representative products of genes from these cell populations are shown in Figure 2. The expression patterns of the 266 genes were categorized into three groups (A, B, and C) and 11 types (Table 1). Group A includes genes expressed in a single specific cell population. Within group A, type I indicates genes expressed only in D0 cells, type II indicates genes expressed only in E14 cells, and type III indicates genes expressed only in G14 cells. In group B, genes expressed in two cell populations are subdivided into four types: type IV for genes expressed

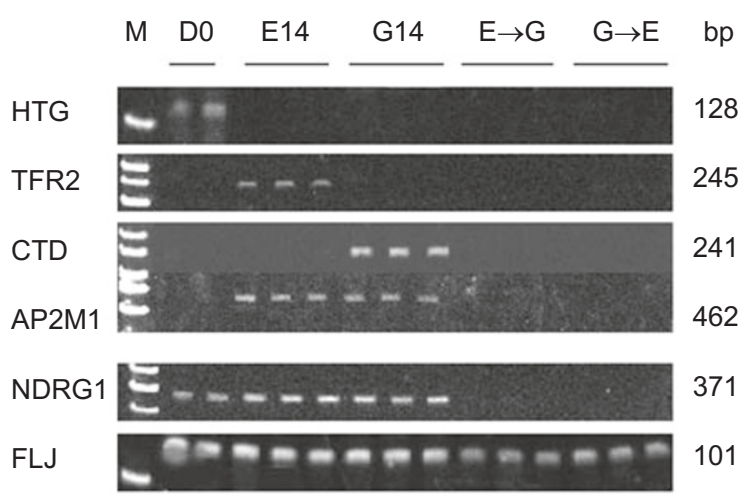

Figure 2 Representative gene-specific products of erythroid and myeloid commitment from HSCs. RAGE-PCR analysis was performed on five cell populations (D0, E14, G14, E14 $\rightarrow$ G14 (labeled as E $\rightarrow$ $\mathrm{G})$ and $\mathrm{G} 14 \rightarrow \mathrm{E} 14$ (labeled as $\mathrm{G} \rightarrow \mathrm{E})$ ). Representative gene-specific expressions were shown on duplicate (D0) or triplicate samples (all other cell populations). M, 50-bp DNA ladder; $H T G$, human transcriptase gene; TFR2, transferrin receptor 2 gene; CTD, human chromosome 19 clone CTD-2245F17; AP2M1, adaptor-related protein complex 2, Mu1 subunit; NDRG1, N-myc downstream-regulated gene 1; FLJ, hypothetical protein FLJ20547.

Table 1 Gene expression patterns of erythroid and myeloid differentiation and conversion of human CD133 ${ }^{+}$cells

\begin{tabular}{|c|c|c|c|c|c|c|c|c|}
\hline \multirow[b]{2}{*}{ Group } & \multicolumn{8}{|c|}{ Gene distribution in cell populations } \\
\hline & Type & D0 & E14 & G14 & $\mathrm{E} 14 \rightarrow \mathrm{G} 14$ & $\mathrm{G} 14 \rightarrow \mathrm{E} 14$ & Gene & Identified \\
\hline \multirow[t]{2}{*}{ A } & I & + & - & - & - & - & 8 & 4 \\
\hline & III & - & - & + & - & - & 23 & 12 \\
\hline \multirow{2}{*}{$\mathrm{B}$} & VI & - & - & + & + & - & 1 & 1 \\
\hline & VII & - & + & + & - & - & 30 & 21 \\
\hline $\mathrm{C}$ & VIII & + & + & - & - & + & 1 & 1 \\
\hline Total & & & & & & & 266 & 145 \\
\hline
\end{tabular}

+, gene expressed; -, gene not detected. D0, human CD133 ${ }^{+}$bone marrow stem cells; E14, D0 cells grown in culture for 14 days with erythropoietin (EPO); G14, D0 cells grown in culture for 14 days with granulocyte-colony stimulating factor (G-CSF); E14 $\rightarrow$ G14, E14 cells grown for another 14 days in culture with G-CSF; G14 $\rightarrow$ E14, G14 cells grown for another 14 days in culture with EPO. Gene, number of genes expressed by RAGE analysis that fell into this grouping. Identified, number of genes in this category that were identified by BLAST searches or by cloning and sequencing. 
in D0 and E14 cells, type V for genes expressed in D0 and G14 cells, type VI for genes expressed in G14 and E14 $\rightarrow$ G14 cells, and type VII for genes expressed in E14 and G14 cells. Group C includes genes expressed in three or more cell populations and is subdivided into four types: type VIII for genes expressed in D0, E14, and G14 $\rightarrow$ E14 cells; type IX for genes expressed in D0, G14, and E14 $\rightarrow$ G14 cells; type X for genes expressed in D0, E14, and G14; and type XI for genes expressed in all five cell populations examined.

Identification of differentially expressed genes in response to EPO and G-CSF

Of the 266 RAGEtags expressed, 145 genes (55\%) were identified during differentiation and switching of erythroid and myeloid lineages by BLAST searches of the Capital Genomix database (51 genes) or by cloning and sequencing of cDNA fragments (94 genes), ranging from $100 \mathrm{bp}$ to 599 $\mathrm{bp}$ in length (average $=259 \mathrm{bp}$ ). Among the 145 identified genes, 116 (80\%) were known genes, 26 genes (18\%) were previously identified genes with unknown functions, and three (2\%) were identified as novel genes (Table 2). One of the novel genes (GenBank accession No. AY591761) was expressed specifically in the G14 myeloid cell population. The two other genes (AY591762 and AY591763) were expressed in the D0, E14 erythroid, and G14 myeloid cell populations, with the highest levels of expression in the E14 and D0 cell population, respectively.

In the RAGE analysis, most genes were not expressed at detectable levels in the E14 $\rightarrow$ G14 and G14 $\rightarrow$ E14 secondary culture populations, although normalization was performed for all five samples in all of eight standardization genes as mentioned in the Materials and Methods section (data not shown). One possible explanation is that more amplification may be necessary to detect the specific cDNA products in these two cell populations because lineagespecific genes may be expressed at low levels in these cells [22]. In addition, the work of others has indicated that lineage-specific genes were not expressed in repopulating cell fractions [23]. It is still uncertain whether silencing of specific gene expression programs occurs in repopulating cells.

\section{Protein profiling of HSCs in response to EPO and G- CSF}

Silver-stained 2-DE images of the five cell populations are shown in Figure 3. D0 cells exhibited 1012 spots, E14 cells exhibited 1434 spots, G14 cells exhibited 1414 spots, E14 $\rightarrow$ G14 cells exhibited 2055 spots, and G14 $\rightarrow$ E14 cells exhibited 3603 spots. E14 and G14 cells shared 762 spots with each other, and both shared 769 protein spots with D0 cells. E14 $\rightarrow$ G14 cells and G14 $\rightarrow$ E14 cells shared 1422 spots with each other, and both shared 911 spots with D0 cells. The protein spots shared between E14 and G14 cells and between $\mathrm{E} 14 \rightarrow \mathrm{G} 14$ and G14 $\rightarrow$ E14 cells were matched and compared with spots in D0 progenitor cells for quantitative analyses. The percentages of shared and specific protein spots expressed on day 14 cells in culture were generally consistent with the distribution of gene-specific RAGE-PCR products expressed in the same populations of cells.

These changes in protein expression appear to reflect responses to alterations in cytokine signals. Representative protein spots expressed and identified with 2-DE and MALDI-MS during erythroid and myeloid development were indicated by arrowheads (Figure 3). Calgranulin B and cathepsin $\mathrm{D}$ are associated with the development of the myeloid lineage, whereas glutathione $S$-transferase (GST) appeared in all five cell populations.

Using 2-DE analysis, we identified a specific cytokineresponding protein, GMFG, which was significantly altered in the differentiation and switching of the erythroid and myeloid lineages from HSCs in response to the cytokine stimulation (Figure 3A-F, number 4). We published part of the 2-DE data (B and $\mathrm{E}$ for spots of number 4) recently [24]. GMFG is one of the GMF family members; another member is glia maturation factor beta. The expression of GMFG gene in five populations of cells studied was analyzed by RT-PCR, and the results showed a constant level of expression among these five populations of cells (data not shown). These data suggest that the 2-DE is a good tool to determine changes of certain proteins, such as GMFG, in response to cytokines in the special culture system.

\section{Co-expression of cell surface marker in cytokine-mediated} lineage development

To investigate the co-expression of lineage-specific antigens in normal lineage development, we analyzed cell surface antigens of cells cultured with EPO or G-CSF by three-color flow cytometry (Figure 4). The alterations in cell surface antigen expression observed in Figure 4 are presented quantitatively in this text as a mean of at least three independent experiments. The CD133 marker expressed in the initial population of $\mathrm{CD} 133^{+}$cells (D0, $>98 \%$; Figure 4 , $\mathrm{Aa}, \mathrm{Ba})$ decreased over time as these cells were committed to erythroid or myeloid lineages under culture conditions. In contrast, an increase in cells expressing CD36 (from 1.1\% to $87.7 \%$; Figure $4, \mathrm{Ca}, \mathrm{Cb}$ ) or $\mathrm{CD} 13$ (from $46.3 \%$ to $98.6 \%$; Figure 4, $\mathrm{Ca}, \mathrm{Ce}$ ) was observed in 14-day cultures with EPO (E14) and G-CSF (G14), respectively. In E14 cells, $76.6 \%$ of CD36-expressing cells co-expressed the CD13 antigen (Figure 4, Cb), whereas in G14 cells, only $6.1 \%$ of CD13-expressing cells co-expressed the CD36 marker (Figure 4, Ce). The fraction of cells expressing CD133 
Table 2 Genes identified in five cell populations during erythroid and myeloid differentiation and switching of human CD133 ${ }^{+}$stem cells

\begin{tabular}{|c|c|c|c|c|c|c|c|}
\hline \multirow[t]{2}{*}{ Type $^{1}$} & \multirow{2}{*}{$\begin{array}{l}\text { GenBank } \\
\text { accession no. }\end{array}$} & \multirow[t]{2}{*}{ Description } & \multicolumn{5}{|c|}{ Scanned intensity (AU) } \\
\hline & & & D0 & E14 & G14 & $\mathrm{E} 14 \rightarrow \mathrm{G} 14$ & $\mathrm{G} 14 \rightarrow \mathrm{E} 14$ \\
\hline & & Genes in single populations & & & & & \\
\hline \multirow[t]{3}{*}{ I } & AF164598 & CDC16 & 50 & & & & \\
\hline & M25768 & Human transcriptase gene (HTG) & 99 & & & & \\
\hline & & E14 (10) & & & & & \\
\hline \multirow[t]{8}{*}{ II } & M91037 & $\mathrm{G} / \mathrm{AGG}$ & & 81 & & & \\
\hline & NM006150 & LMO6 & & 181 & & & \\
\hline & AL356580 & Clone RP11-383H17 & & 156 & & & \\
\hline & AL078621 & Clone RP11-395L14 & & 89 & & & \\
\hline & XM 088459 & KIAA0310 & & 67 & & & \\
\hline & AC010467 & FZF195 & & 59 & & & \\
\hline & AC011742 & BAC clone RP11-214J9 & & 38 & & & \\
\hline & & G14 (12) & & & & & \\
\hline \multirow[t]{8}{*}{ III } & AJ297391 & TSG gene & & & 168 & & \\
\hline & AC025755 & Clone CTD-2045M21 & & & 124 & & \\
\hline & AK056116 & Clone NT2RI2001230 & & & 176 & & \\
\hline & AC092070 & Clone CTD-2245F17 & & & 237 & & \\
\hline & AC072061 & BAC clone RP11-467D6 & & & 143 & & \\
\hline & AY591761 & HSPCG- $1^{2}$ & & & 167 & & \\
\hline & & Genes in two populations & & & & & \\
\hline & & D0 and E14 (7) & & & & & \\
\hline \multirow[t]{8}{*}{ IV } & U02310 & FKHR mRNA & 13 & 41 & & & \\
\hline & L78294 & NCOR1 & 127 & 36 & & & \\
\hline & ВC007602 & MBLR & 14 & 17 & & & \\
\hline & AF099976 & Schlafen-related & 27 & 31 & & & \\
\hline & NM015540 & DKFZP727M111 protein & 16 & 19 & & & \\
\hline & ВC005869 & Clone IMAGE: 2966557 & 22 & 17 & & & \\
\hline & AC069546 & Clone RP11-507K13 & 31 & 24 & & & \\
\hline & & D0 and G14 (3) & & & & & \\
\hline $\mathrm{V}$ & AP141334 & APOB48R & 20 & & 60 & & \\
\hline
\end{tabular}


Table 2 Genes identified in five cell populations during erythroid and myeloid differentiation and switching of human CD133 ${ }^{+}$stem cells (continued)

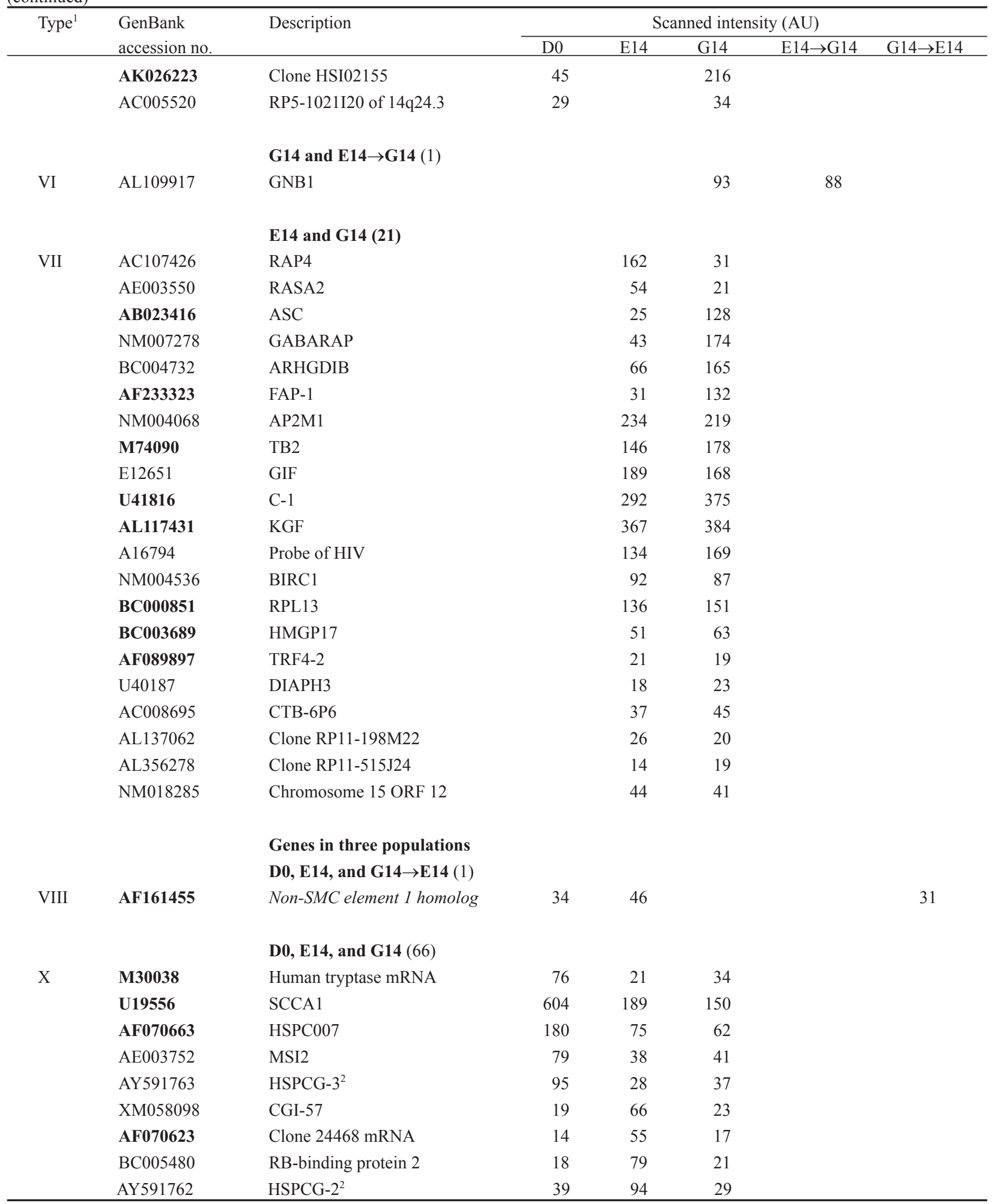


Table 2 Genes identified in five cell populations during erythroid and myeloid differentiation and switching of human CD133 ${ }^{+}$stem cells (continued)

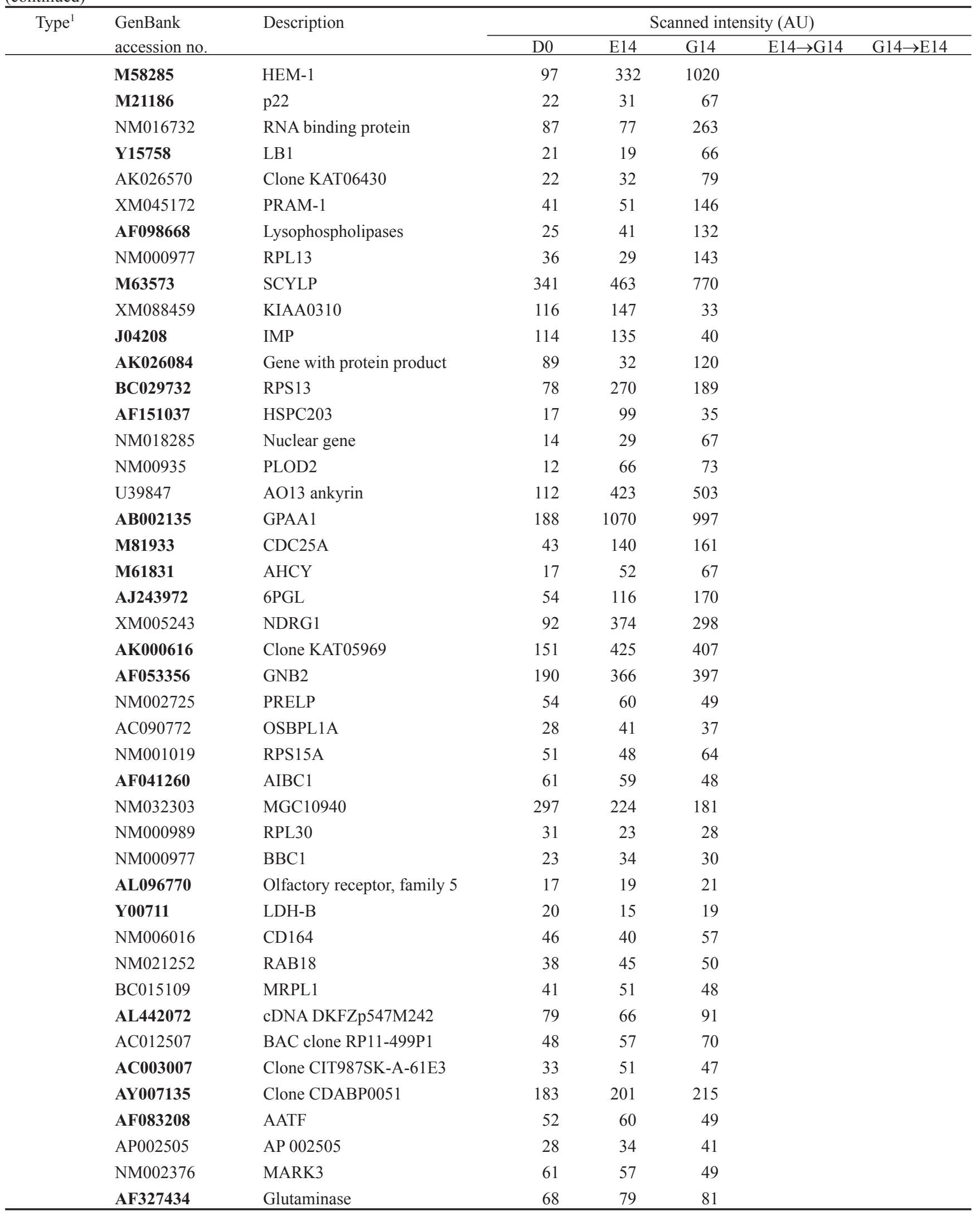


Table 2 Genes identified in five cell populations during erythroid and myeloid differentiation and switching of human CD133 ${ }^{+}$stem cells (continued)

\begin{tabular}{|c|c|c|c|c|c|c|c|}
\hline \multirow[t]{2}{*}{ Type $^{1}$} & \multirow{2}{*}{$\begin{array}{l}\text { GenBank } \\
\text { accession no. }\end{array}$} & \multirow[t]{2}{*}{ Description } & \multicolumn{5}{|c|}{ Scanned intensity (AU) } \\
\hline & & & D0 & E14 & G14 & $\mathrm{E} 14 \rightarrow \mathrm{G} 14$ & $\mathrm{G} 14 \rightarrow \mathrm{E} 14$ \\
\hline & NM 001960 & EEF1D & 36 & 41 & 52 & & \\
\hline & U 27196 & FZF & 64 & 79 & 83 & & \\
\hline & AC064863 & Clone RP11-392M11 & 45 & 65 & 58 & & \\
\hline & NM005857 & Zinc metalloproteinase & 44 & 30 & 26 & & \\
\hline & AC073215 & BAC clone RP11-501L9 & 31 & 27 & 22 & & \\
\hline & XM117540 & Homo sapiens LOC151162 & 33 & 19 & 24 & & \\
\hline & AL023694 & Clone 511E16 & 21 & 16 & 14 & & \\
\hline & & Genes in all five population & & & & & \\
\hline \multirow[t]{14}{*}{ XI } & AL365398 & Clone RP11-430L14 & 230 & 209 & 245 & 203 & 299 \\
\hline & NM024589 & FLJ22386 & 88 & 91 & 99 & 67 & 83 \\
\hline & ВC014794 & FLJ 20574 & 68 & 56 & 81 & 72 & 69 \\
\hline & L39211 & MCPTI & 78 & 117 & 83 & 97 & 77 \\
\hline & U032269 & Cap Z & 99 & 89 & 79 & 56 & 67 \\
\hline & AK023492 & Clone PLACE1002514 & 144 & 158 & 157 & 149 & 123 \\
\hline & AC074091 & Clone RP11-158I13 & 66 & 87 & 73 & 54 & 44 \\
\hline & AF228552 & Mammary tumor virus $\mathrm{C} 3 \mathrm{H}$ & 121 & 101 & 135 & 94 & 117 \\
\hline & AF040257 & TNTR & 91 & 117 & 72 & 67 & 85 \\
\hline & AF254260 & TUFT1 & 151 & 143 & 129 & 114 & 123 \\
\hline & AK022125 & Clone HEMBB1002218 & 77 & 69 & 94 & 79 & 86 \\
\hline & D83777 & KIAA0193 & 288 & 269 & 291 & 214 & 274 \\
\hline & NM008722 & Npm1 & 39 & 60 & 55 & 48 & 44 \\
\hline & AF090697 & Napor-3 & 67 & 83 & 79 & 74 & 72 \\
\hline
\end{tabular}

${ }^{1}$ Matched to the type of genes as categorized in Table 1.

${ }^{2}$ Identified as novel fragments of genes in this study. D0, human CD133 ${ }^{+}$bone marrow stem cells; E14, D0 cells grown in culture for 14 days with erythropoietin (EPO); G14, D0 cells grown in culture for 14 days with granulocyte-colony stimulating factor (G-CSF); E14 $\rightarrow$ G14, E14 cells grown for another 14 days in culture with G-CSF; G14 $\rightarrow$ E14, G14 cells grown for another 14 days in culture with EPO. ID in bold indicates genes analyzed for biological process in Figure 6. Scanned intensities are normalized values obtained from SYBR Green-stained gels using a FluorImager. No information under the 'Scanned Intensity' label indicates that the gene is undetectable. 
A

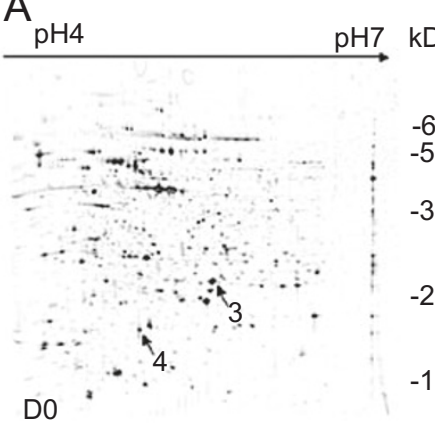

D

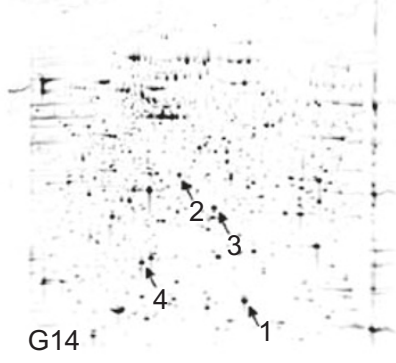

B

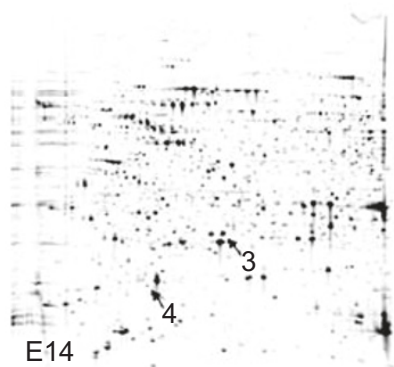

C

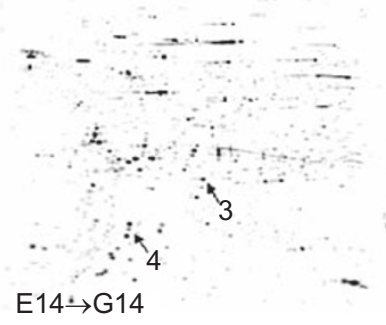

$\mathrm{F}$

$E$

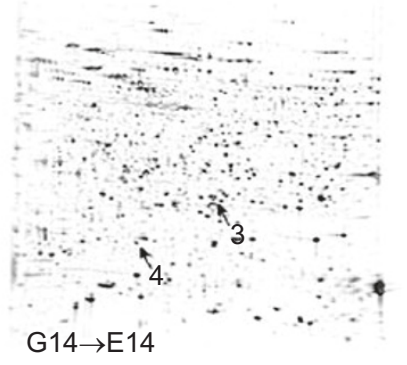

\begin{tabular}{|lllc|}
\hline \multicolumn{4}{|c|}{$\begin{array}{c}\text { Representative proteins expressed } \\
\text { during lineage development }\end{array}$} \\
No\# & Accession & Name & Distribution \\
1.gi & 7417327 & Calgranulin B & G14 \\
2.gi & 5822085 & Cathepsin D (chain B) & G14 \\
3.gi & 2981694 & Glutathione S-transferase & All the stages \\
4.gi & 4758440 & Glia maturationfactor gamma all the stages \\
\hline
\end{tabular}

Figure 3 Protein profiles of HSCs undergoing erythroid and myeloid differentiation. Cell lysates $\left(5 \times 10^{5}\right.$ cells) from each sample were subjected to two-dimensional electrophoresis ( $\mathrm{pH} 4-7$ ), followed by silver staining. Molecular mass markers are indicated to the right of panel A. Proteomes of the five cell populations are shown in panels A-E. Numbered arrows indicate protein spots shared among the cell populations. Panel $\mathbf{F}$ provides a list of representative proteins expressed in different cell populations. The gels shown are representative of those from at least two independent experiments.

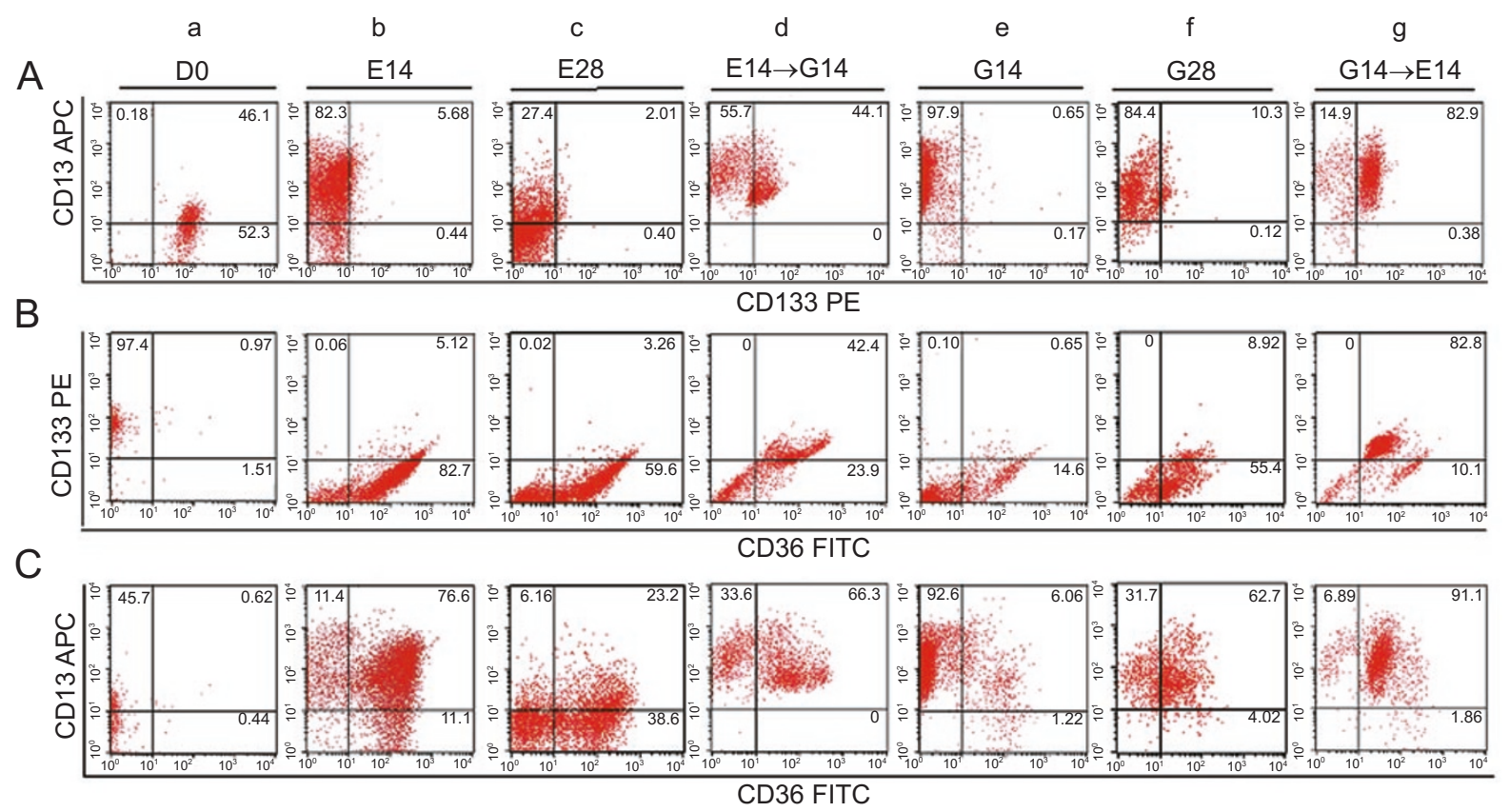

Figure 4 Changes of lineage-specific cell surface markers in erythroid and myeloid cells. The expression levels of CD133 (for stem cells), CD36 (for erythroid cells), and CD13 (for myeloid cells) during erythroid and myeloid differentiation of purified CD133 cells were analyzed in seven cell populations using three-color flow cytometry. Cells were stained with combinations of CD13-APC, CD36-FITC, and CD133-PE. 
only was $<1 \%$ in E14 (Figure 4, Ab, Bb) or G14 (Figure $4, \mathrm{Ae}, \mathrm{Be}$ ) cell populations, consistent with a previously published study [9]. Five to six percent of CD133-expressing cells co-expressed the CD13 antigen (Figure 4, Ab) or the CD36 antigen (Figure 4, Bb) in E14 cells, whereas in G14 cells, $<1 \%$ of CD133-expressing cells co-expressed CD13 (Figure 4, Ae) or CD36 (Figure 4, Be). However, when E14 cells progressed to the E14 $\rightarrow \mathrm{G} 14$ population, there was a large increase in the percentage (from about 5\% to $42-44 \%$ ) of co-expression of CD133 with CD36 (Figure 4, Bb, Bd) or CD13 (Figure 4, Ab, Ad). Similarly, in the G14 $\rightarrow$ E14 culture, a high percentage $(>80 \%)$ of cells were found to co-express CD13 and CD133, CD133 and CD36, or CD13 and CD36 (Figure 4, Ag, Bg, Cg). However, a predominance of cells co-expressing these antigens was not observed in E28 (Figure 4, Ac, Bc, Cc) or G28 cells (Figure 4, Af, Bf, Cf). The data demonstrate that the level of cells co-expressing these antigens was much lower in E28 and G28 than what was seen for E14 $\rightarrow$ G14 and G14 $\rightarrow$ E14. The finding of progenitor antigen reappearance was reported previously [25] in studies where specific phenotypic markers showed reversible changes.

\section{Tissue-specific expression and effects of GMFG on hema- topoietic cells}

Expression of GMFG in normal adult human tissues was studied using the Northern blot analysis. Results show that GMFG is highly expressed in spleen and thymus (Figure $5 \mathrm{~A}$ ) and the highest expression is detected in peripheral blood leukocyte, which is consistent with a previous report by Inagaki et al. [26]. The study demonstrates that GMFG gene is specifically and highly expressed in the blood system.

To gain insight into the effects of GMFG on hemato-
A

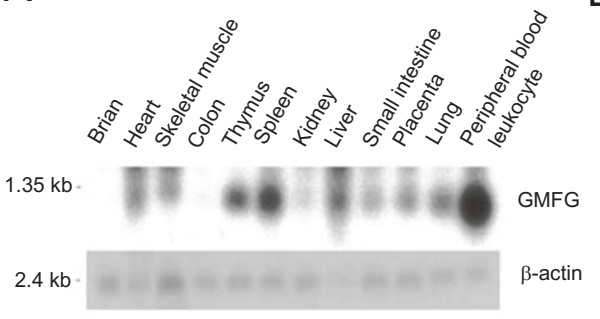

$B$

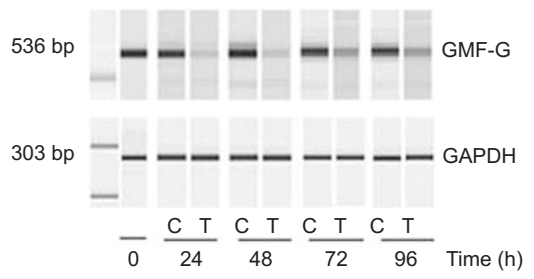

C

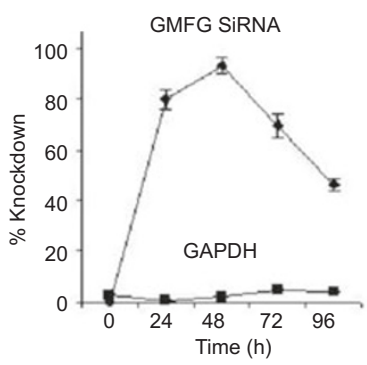

D
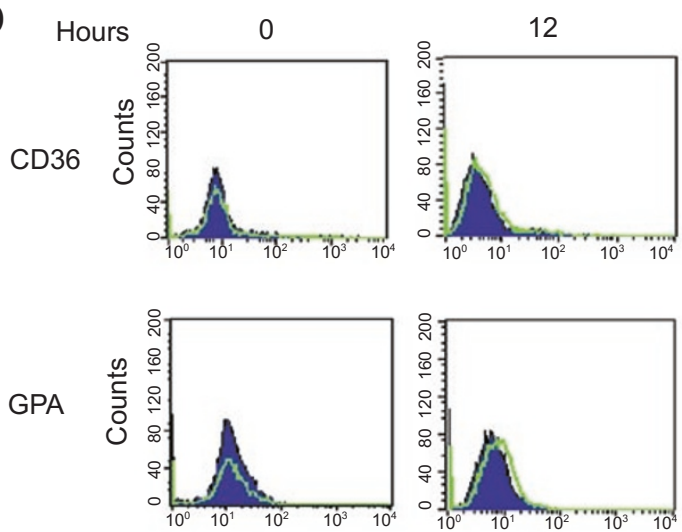
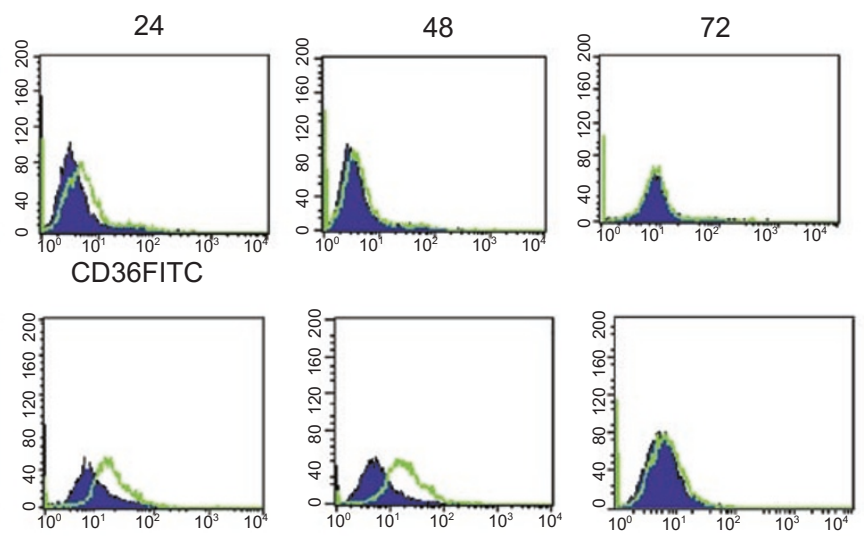

GPAFITC

Figure 5. Expression of GMFG in tissues and effects of its siRNA in K562 cells. (A) Northern bolt analysis. Hybridization with the GMFG cDNA probe revealed a transcript with the size of approximately $0.9 \mathrm{~kb}$. The pattern of GMFG expression in the human multiple tissues showed highest expression in blood system (upper). The same blot was reprobed with b-actin as a control for loading quality. The size marker is indicated on the left. (B) Knockdown efficiency of GMFG siRNA in K562 cells. K562 cells transfected with GMFG siRNA, Control siRNA or nontransfected K562 cells ( 0 h) were used for RNA extraction. Qualitative RT-PCR analyses of GMFG mRNA expression were carried out in K562 cells at the indicated times. Ethidium bromide-stained agarose gel is a representative of three independent experiments. (C) The knockdown efficiency of GMFG expression is time-dependent. The housekeeping gene, GAPDH, remains constant throughout the different treatments and time intervals. (D) Upregulation of CD36 and GPA surface expression by GMFG siRNA in K562 cells. K562 cells were treated with GMFG siRNA ( $2 \mu \mathrm{g} / \mathrm{ml})$, fixed at the indicated time points, and then reacted with the antibodies indicated for flow cytometry. The values for controls (dotted plot histograms) and CD36 and GPA (dotted lines) are indicated. 
poietic cells, human leukemic K562 cells were transfected with GMFG siRNA or control siRNA. The GMFG mRNA level was reduced dramatically (up to $93 \%$ ) in a time-dependent manner (Figure 5B and 5C). The gene expression level remained unaffected by control siRNA, demonstrating the specificity of GMFG siRNA. Therefore, the siRNA technology will allow further analysis of GMFG functions in human leukemic K562 cells.

The expression levels of CD133, CD36, GPA, and CD13 markers in transfected human leukemic K562 cells were analyzed using specific antibodies. GMFG siRNA clearly induced the expression of lineage-specific surface markers (CD36 and GPA) on K562 cells (Figure 5D), indicating that GMFG can regulate erythroid differentiation. The result was consistent with the observation in 2-DE (Figure 3) that the level of GMFG protein was reduced with erythroid commitment in response to EPO induction (Figure 3). The expressions of CD133 and CD13 markers were not affected by GMFG siRNA in K562 cells (data not shown). Our results with GMFG are consistent with the promoter analysis of GMFG by Kawai et al. [27], in which these authors demonstrated that its bi-directional promoter region contains binding sites for various hematopoietic transcription factors. Further study should be conducted in normal hematopoietic cells to further investigate the roles of GMFG in hematopoiesis.

Comparison of biological processes of genes expressed in $H S C s$ in response to EPO and G-CSF

To provide a preliminary framework for understanding the biological processes associated with the genes in erythroid and myeloid lineage cells, we merged two sets of expressed genes (indicated by bold in Table 2) from erythroid and myeloid cells and mapped the combined set onto the Gene Ontology hierarchy for comparative analysis. The resulting map is a tree structure in which the lines stand for the biological processes and each node (dot) represents a Gene Ontology identifier (Figure 5). On this tree, the nodes of biological process terms matching the gene(s) in the erythroid, myeloid, or both sets were shown as red, blue, and yellow dots, respectively. Several conclusions can be derived from the comparison. First, genes uniquely expressed in erythroid and myeloid lineages mapping to many nodes is common for both the general (shown at top) and specialized (at bottom) processes, including 'development', 'cell communication', and 'response to stimulus' (dots 2, 5, and 7). Second, genes expressed specifically in the myeloid lineage participated mainly in the processes of 'death', 'regulation of enzyme activity', and 'G-protein signalling' (dots $8,14,29$, and 34), whereas genes in the erythroid lineage attended the processes of 'macromolecule metabolism', 'programmed cell death,' and 'transcription regulation' (dots 17, 19, and 33). Third, some genes map to the nodes of branch points where the process clusters match one gene set and later derive into the other set within the biological processes. For example, 'regulation of biological process' and 'regulation of programmed cell death' (dots 4 and 22) are associated with a cluster that is first a myeloid set, then becomes an erythroid set, and 'cellular process' (dot 1) is associated with a cluster that is first an erythroid set, then becomes a myeloid set. Finally, a biological process may include many genes in the erythroid and myeloid lineages, and a gene may support or participate in several biological processes.

\section{Discussion}

In this study, we developed a unique culture system to induce erythroid- and myeloid-enriched lineages simultaneously from the same source of HSCs to identify patterns of differentially expressed genes and proteins, to observe changes of lineage-specific cell surface antigens, and to analyze biological pathways of the genes expressed during these two lineage commitment and conversion.

We found that some genes were expressed only in the erythroid or myeloid lineage and other genes were expressed in two or more of the five cell populations examined. Genes expressed in a single population of cells may be related to the proliferation or differentiation of those cells. For example, the $C D C 16$ (cell division control protein 16) and SDP35 (human mRNA for putative cell cycle control protein) genes (Table 2, I) were identified only in D0 stem cells; the TFR2 (human transferrin receptor 2) and $G / A G G$ (G gamma globin and A gamma globin) genes (Table 2, II) were exclusively expressed in EPO-stimulated erythroid cells (E14), and the CD18 gene (Table 2, III) was expressed only in G-CSF-stimulated myeloid cells (G14). These data suggest that these genes are required for HSCs, erythroid, and myeloid development, respectively. The Non-SMC element 1 homolog gene (Table 2, VIII) was expressed in the D0 and E14 cells, but not in G14 cells. However, it reappeared when G14 cells were exposed to EPO for another 14 days (G14E14 cells). In contrast, the GNBI (guanine nucleotide-binding protein beta polypeptide 1) gene (Table 2, VI) was expressed in G14 cells but not in E14 cells; it reappeared after E14 cells were stimulated with G-CSF for additional 14 days (E14 $\rightarrow$ G14 cells). The specific relationships of the Non-SMC element 1 homolog gene with EPO and the GNB1 gene with G-CSF exposure suggest that these genes may be crucial for erythroid or myeloid regulation, respectively, and that they could be regulated by changes in the cell environment. Biological processes that were significantly related to genes expressed in erythroid cells included 'iron ion transport' (Figure 6, 
dot 35). The TFR2 gene has previously been associated with erythroid development; its increased expression reflects the requirement of iron for making hemoglobin [28]. Biological process mapped the fMLP-R26 (fMet-Leu-Phe Receptor 26) gene (Table 2, type III) to 'activation of MAPK' and 'G-protein signalling' (Figure 6, dots 28 and 34) in myeloid lineage which is consistent with a previous report that G-protein-coupled chemotactic fMLP activated the heterodimeric phosphoinositide-3 kinase in enhancing superoxide formation in neutrophils [29].

Genes co-expressed in E14 and G14 cells (Table 2, type VII) and in D0, E14, and G14 cells (Table 2, type X) may be required at some specific developmental stages and may be essential for these two closely related developmental lineages, as reported previously [30]. Co-expression during erythroid and myeloid development was also observed at the protein and cellular surface antigen levels in the 14-day cell cultures (Figures 3 and 4). The comparative analysis of the biological processes of erythroid and myeloid cells demonstrated that a large fraction of genes co-expressed in these two lineages support 'core biological processes,' such as 'development' (Figure 6, dot 2) and 'metabolism' (dot 10). These shared biological processes also include 'cell communication' (dot 5) and 'response to stimulus' (dot 7), implying that the cross-lineage genes in these nodes may represent more plastic characteristics of their specific traits [31, 32], and may contribute to our understanding of 'lineage switch or plastics' as they are influenced by cell environment alterations.

Recently, oligonucleotide microarrays were used for the gene expression profiling of untreated CD133 ${ }^{+} \mathrm{HSCs}$ $\left(\mathrm{CD} 133^{+}\right.$vs $\left.\mathrm{CD} 133^{-}\right)[33,34]$. Both studies used the same

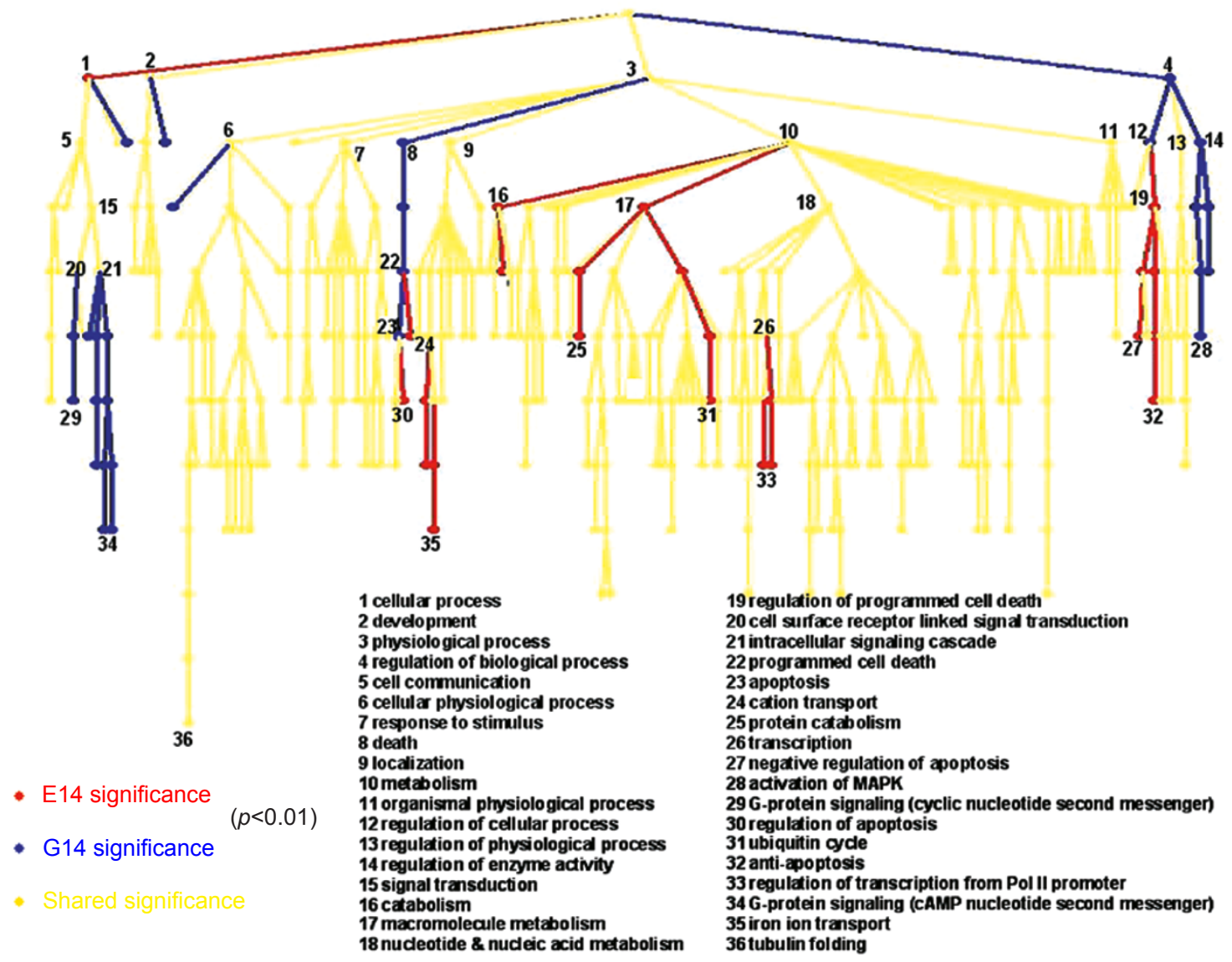

Figure 6 Comparison mapping of genes expressed in erythroid and myeloid development and differentiation to biological processes. The tree structure (dots and connecting paths) represents those categories (dots) in the Gene Ontology hierarchy for biological processes that matched at least one gene expressed in erythroid or myeloid lineage cells (day 14 of cultures, E14, and G14 populations). More than 300 process categories are shown in this map. Clusters on the tree are the biological processes matching at one or more genes in the erythroid lineage (red dots), the myeloid lineage (blue dots), and both (yellow dots). Selected dots of process categories are marked with numbers and listed under the tree map. 
procedures for enrichment of $\mathrm{CD} 133^{+}$cells, purification of RNA, amplification and labeling of RNA probes, and almost the same oligonucleotide microarrays (HG-U133A from Affymetrix), GeneChip scanners, and GeneChip operating software for data analyses. One study identified 690 differentially expressed genes and another identified 584 differentially expressed genes; however, some were inconsistent between these two studies [33, 34]. Here, we analyzed the expression patterns of gene, protein and cell surface antigen, and the biological process of the related genes in erythroid and myeloid differentiation and switching of CD133 ${ }^{+} \mathrm{HSCs}$ in response to EPO and G-CSF. In this in vitro study of normal erythropoiesis and granulopoiesis, we observed morphologically that erythroid and myeloid lineages could be switched depending on the culture conditions (shift of cytokines) of CD $133^{+}$HSCs. We also observed the co-expression of erythroid-specific genes and proteins with myeloid-specific genes, and proteins during the two-lineage development and differentiation in response to cytokines. Furthermore, our flow cytometry data showed that the proportion of cells of one lineage expressing specific markers of another lineage increased after the shift of cytokines, and vice versa (Figure 4). These data are consistent with recently published studies [35-37] in which the authors demonstrated that growth factors could regulate cell-fate decision. Data from this study support the hypothesis that differentiated HSCs (E14 or G14) cells can still be redirected to develop into myeloid or erythroid cells when EPO is replaced with G-CSF or GCSF with EPO, respectively. The molecular mechanisms of this switch leading to alternative commitment need to be further studied.

We propose three possible models to explain our data. In model 1, both E14 and G14 cells are a mixture of committed, mature, and progenitor cells. After shift of the cytokine, the progenitor subpopulation (if any) heavily proliferates and differentiates into the other lineage cells. In model 2, after changing of the cytokine, some early committed cells, which have not yet lost proteins or markers 'specific' for the other lineage, change their mind and partially make a right or left 'turn' (if not a 'U turn') to go back to the 'CMP' stage and then choose the alternate lineage developmental pathway. In model 3, after the shift of cytokine, late committed erythroid cells in the G14 cells or myeloid cells in the E14 cells may respond to a 'selection mechanism' by the means of proliferation in their favorable environment of G14 $\rightarrow \mathrm{E} 14$ or $\mathrm{E} 14 \rightarrow \mathrm{G} 14$ cultures, respectively.

Relative to model 1, the residual progenitor (CD133+only) cells might contribute to the switch, although only a small number of $\mathrm{CD}_{133^{+}}$cells $(<1 \%)$ are retained in 14-day cultures. However, it is difficult to explain the populations of cells observed in 28-day cultures started with less than
$1 \%$ of $\mathrm{CD} 133^{+}$cells, in which all the newly derived $\mathrm{CD} 36^{+}$ cells incremented from $\sim 15 \%$ in G14 (Figure $4, \mathrm{Be}$ ) to $\sim 93 \%$ in G14 $\rightarrow$ E14 (Figure 4, Bg). For the $1 \%$ of progenitor cells to proliferate until they contribute more than $78 \%$ increment $(93 \% \sim 15 \%)$ of cells, the total number of cells would have to increase $>78$-fold. Our previous data indicate that the total number of cells increases approximately 2-to-3-fold from day 14 to day 28 (for E14 to E14 $\rightarrow$ G14 cells and for G14 to G14 $\rightarrow$ E14 cells) [21]. Using CD34 ${ }^{+}$ CD45RA ${ }^{\mathrm{IO}} \mathrm{CD} 71^{\mathrm{IO}}$ cells, other scientists have shown that no such single $\mathrm{CD} 34^{+}$was alive after 14-days of culture [38], which means that these progenitor cells could not keep 'single' for more than 14 days; they either die or divide into committed lineage cells under the culture condition used. Based on the above reasons, the possibility of model 1 seems unlikely. Regarding the model 3, our colony-forming assay in methylcellulose (data not shown) suggests that the late committed erythroid or myeloid lineage cells may continue to proliferate and further mature when they grow in appropriate conditions, but these committed cells are not involved in the observed cell switching from one lineage to the other. Thus, we could probably eliminate the possibility of model 3 .

Our data and other studies [39] have demonstrated that the genes co-expressed in erythroid and myeloid lineages reflect a common physiological differentiation process for both lineages. Co-expressed populations of erythroid and myeloid progenitors represent subsets retaining the ability of either erythropoiesis or granulopoiesis development in response to changes of cytokines. When we carried out semisolid cultures for colony assays, we observed a significant erythroid and myeloid colony formation from sorted cells co-expressing both erythroid- and myeloid-specific markers in the presence of cytokines (data not shown). The genes co-expressed on erythroid and myeloid progenitors may play the main role in lineage switch in normal hematopoiesis, acting as molecular events, affecting the balance of lineage-specific transcription factors, such as GATA-1 and PU.1 [40], or C/EBP $\alpha$ [7, 41], and leading CMPs to follow the erythroid or myeloid developmental pathway. Therefore, model 2 can probably be used to explain the switch-related events induced by cytokine changes. In myelodysplastic and myeloproliferative disorders and in some leukemias, the progenitor cells may stop differentiating at some intermediate point(s) in the processes in which cross-lineage genes are co-expressed because of 'confusing' signals at the intersection points, failing to become mature blood cells of either the erythroid or myeloid lineage.

In summary, we developed a unique culture system to induce erythroid- and myeloid-enriched lineages simultaneously from the same source, HSCs, which provides both practical and theoretical platforms for further studies in this 
area. We identified the gene expression patterns of five cell populations, representative of hematopoietic development from progenitors to mature erythroid and myeloid lineage cells, which provides candidate genes for further studies and may also provide an insight into the mechanisms underlying the regulation of differentiation and switching of these lineages. Our observation supports the hypothesis that differentiated HSCs (E14 or G14) can still be redirected to produce myeloid or erythroid cells when EPO is replaced with G-CSF in erythroid-cultured medium or G-CSF with EPO under myeloid-cultured condition, respectively. Our results suggest that genes or proteins co-expressed in erythroid and myeloid lineages may be essential for lineage maintenance and switching in hematopoiesis. Further studies with global genes in hematopoiesis or in vivo confirmation of the apparent ability of these 'bi-switching' cells may offer new targets or new strategies for the treatment of hematopoietic disorders.

\section{Acknowledgments}

We thank Drs Jim Mei (Lifenhancer Inc.) and Honghui Wan (NIEHS) for valuable assistance with gene sequencing analysis, Dr Sheng Zhong (DBIGB, University of Illinois) for valuable discussion and help with GoSurfer, Dr David Chee (MCHB, NIH) for assistance with gene data analyses, and Drs Peggy Hsieh and R Daniel Camerini-Otero of NIDDK for assistance with 2-DE analyses.

\section{References}

1 Xie H, Ye M, Feng R, Graf T. Stepwise reprogramming of B cells into macrophages. Cell 2004; 117:663-676.

2 Klinken SP, Alexander WS, Adams JM. Hemopoietic lineage switch: v-raf oncogene converts Emu-myc transgenic B cells into macrophages. Cell 1988; 53:857-867.

3 Moore BE, Quesenberry PJ. The adult hemopoietic stem cell plasticity debate: idols vs new paradigms. Leukemia 2003; 17:1205-1210.

4 Wang A, Pierce A, Judson-Kremer K, et al. Rapid analysis of gene expression (RAGE) facilitates universal expression profiling. Nucleic Acids Res 1999; 27:4609-4618.

5 Greaves MF, Chan LC, Furley AJ, Watt SM, Molgaard HV. Lineage promiscuity in hemopoietic differentiation and leukemia. Blood 1986; 67:1-11.

6 Ribadeau Dumas A, Hamouda NB, Leriche L, et al. Establishment and characterization of a new human erythroleukemic cell line, ERY-1. Leuk Res 2004; 28:1329-1339.

7 Schwieger M, Lohler J, Fischer M, Herwig U, Tenen DG, Stocking C. A dominant-negative mutant of C/EBPalpha, associated with acute myeloid leukemias, inhibits differentiation of myeloid and erythroid progenitors of man but not mouse. Blood 2004; 103:2744-2752.

8 Matsumoto K, Yasui K, Yamashita N, et al. In vitro proliferation potential of AC133 positive cells in peripheral blood. Stem Cells 2000; 18:196-203.
9 Ruzicka K, Grskovic B, Pavlovic V, Qujeq D, Karimi A, Mueller MM. Differentiation of human umbilical cord blood CD133+ stem cells towards myelo-monocytic lineage. Clin Chim Acta 2004; 343:85-92.

10 Summers YJ, Heyworth CM, de Wynter EA, Hart CA, Chang J, Testa NG. AC133+ G0 cells from cord blood show a high incidence of long-term culture-initiating cells and a capacity for more than 100 million-fold amplification of colony-forming cells in vitro. Stem Cells 2004; 22:704-715.

11 Tjonnfjord GE, Steen R, Veiby OP, Egeland T. Lineage commitment of CD34+ human hematopoietic progenitor cells. Exp Hematol 1996; 24:875-882.

12 van Lochem EG, van der Velden VH, Wind HK, te Marvelde JG, Westerdaal NA, van Dongen JJ. Immunophenotypic differentiation patterns of normal hematopoiesis in human bone marrow: reference patterns for age-related changes and disease-induced shifts. Cytometry B Clin Cytom 2004; 60:1-13.

13 Scicchitano MS, McFarland DC, Tierney LA, Narayanan PK, Schwartz LW. In vitro expansion of human cord blood CD36+ erythroid progenitors: temporal changes in gene and protein expression. Exp Hematol 2003; 31:760-769.

14 Terstappen LW, Safford M, Loken MR. Flow cytometric analysis of human bone marrow. III. Neutrophil maturation. Leukemia 1990; 4:657-663.

15 Ashburner M, Ball CA, Blake JA, et al. Gene ontology: tool for the unification of biology. The Gene Ontology Consortium. Nat Genet 2000; 25:25-29.

16 Zhong S, Storch KF, Lipan O, Kao MC, Weitz CJ, Wong WH. GoSurfer : a graphical interactive tool for comparative analysis of large gene sets in gene ontology space. Appl Bioinform 2004; 3:261-264.

17 Storch KF, Lipan O, Leykin I, et al. Extensive and divergent circadian gene expression in liver and heart. Nature 2002; 417:7883.

18 May T, Hauser H, Wirth D. Transcriptional control of SV40 Tantigen expression allows a complete reversion of immortalization. Nucleic Acids Res 2004; 32:5529-5538.

19 Lui WO, Foukakis T, Liden J, et al. Expression profiling reveals a distinct transcription signature in follicular thyroid carcinomas with a PAX8-PPAR(gamma) fusion oncogene. Oncogene 2005; 24:1467-1476.

20 Wang Z, Neuburg D, Li C, et al. Global gene expression profiling in whole-blood samples from individuals exposed to metal fumes. Environ Health Perspect 2005; 113:233-241.

21 Chen L, Zhang J, Tang DC, Fibach E, Rodgers GP. Influence of lineage-specific cytokines on commitment and asymmetric cell division of haematopoietic progenitor cells. Br J Haematol 2002; 118:847-857.

22 Krause DS. Regulation of hematopoietic stem cell fate. Oncogene 2002; 21:3262-3269.

23 Zinovyeva MV, Zijlmans JM, Fibbe WE, Visser JW, Belyavsky AV. Analysis of gene expression in subpopulations of murine hematopoietic stem and progenitor cells. Exp Hematol 2000; 28:318-334.

24 Shi Y, Chen L, Liotta LA, Wan HH, Rodgers GP. Glia maturation factor gamma (GMFG): a cytokine-responsive protein during hematopoietic lineage development and its functional genomics analysis. Genomics Proteomics Bioinform 2006; In press.

25 Sato T, Laver JH, Ogawa M. Reversible expression of CD34 by murine hematopoietic stem cells. Blood 1999; 94:2548-2554. 
26 Inagaki M, Aoyama M, Sobue K, et al. Sensitive immunoassays for human and rat GMFB and GMFG, tissue distribution and agerelated changes. Biochim Biophys Acta 2004; 1670:208-216.

27 Kawai Y, Asai K, Miura Y, et al. Structure and promoter activity of the human glia maturation factor-gamma gene: a TATA-less, GC-rich and bidirectional promotor. Biochim Biophys Acta 2003; 1625:246-252.

28 Reya T, Morrison SJ, Clarke MF, Weissman IL. Stem cells, cancer, and cancer stem cells. Nature 2001; 414:105-111.

29 Momose H, Kurosu H, Tsujimoto N, et al. Dual phosphorylation of phosphoinositide 3-kinase adaptor Grb2-associated binder 2 is responsible for superoxide formation synergistically stimulated by Fc gamma and formyl-methionyl-leucyl-phenylalanine receptors in differentiated THP-1 cells. J Immunol 2003; 171:42274234.

30 Golay J, Introna M, Graf T. A single point mutation in the v-ets oncogene affects both erythroid and myelomonocytic cell differentiation. Cell 1988; 55:1147-1158.

31 Robb L, Lyons I, Li R, et al. Absence of yolk sac hematopoiesis from mice with a targeted disruption of the scl gene. Proc Natl Acad Sci USA 1995; 92:7075-7079.

32 Shalaby F, Ho J, Stanford WL, et al. A requirement for Flk1 in primitive and definitive hematopoiesis and vasculogenesis. Cell 1997; 89:981-990.

33 Toren A, Bielorai B, Jacob-Hirsch J, et al. CD133-positive hematopoietic stem cell "stemness" genes contain many genes mutated or abnormally expressed in leukemia. Stem Cells 2005;
23:1142-1153.

34 Jaatinen T, Hemmoranta H, Hautaniemi S, et al. Global gene expression profile of human cord blood-derived $\mathrm{CD} 133^{+}$cells. Stem Cells 2006; 24:631-641.

35 Kondo M, Scherer DC, Miyamoto T, et al. Cell-fate conversion of lymphoid-committed progenitors by instructive actions of cytokines. Nature 2000; 407:383-386.

36 Haughn L, Hawley RG, Morrison DK, von Boehmer, Hockenbery DM. BCL-2 and BCL-XL restrict lineage choice during hematopoietic differentiation. J Biol Chem 2003; 278:25158-25165.

37 Zhao S, Weinreich MA, Ihara K, Richard RE, Blau CA. In vivo selection of genetically modified erythroid cells using a jak2based cell growth switch. Mol Ther 2004; 10:456-468.

38 Mayani H, Dragowska W, Lansdorp PM. Lineage commitment in human hemopoiesis involves asymmetric cell division of multipotent progenitors and does not appear to be influenced by cytokines. J Cell Physiol 1993; 157:579-586.

39 Akashi K. Lineage promiscuity and plasticity in hematopoietic development. Ann N Y Acad Sci 2005; 1044:125-131.

40 Roeder I, Glauche I. Towards an understanding of lineage specification in hematopoietic stem cells: a mathematical model for the interaction of transcription factors GATA-1 and PU.1. J Theor Biol 2006; 241:852-865.

41 Suh HC, Goova J, Renn K, Friedman AD, Johnson PF, Keller JR. C/EBP $\alpha$ determines hematopoietic cell fate in multipotential progenitor cells by inhibiting erythroid differentiation and inducing myeloid differentiation. Blood 2006; 107:4308-4316. 